(8) Will not the escape of the bile produce dangerous or fatal peritonitis? - liven the escape of bile into the peritoneal cavity, which would naturally excite great apprehension, seems to be more of a theoretical than a practical objection. In only two cases of the twenty was any such discharge of bile observed. 'This gave no it trouble, as it escaped externally in both instances. Pavy has stated that no harm arose from such a free escape of the bile into the peritoneal cavity in his experiments in dogs; and Lane ${ }^{7}$ has reported a case of probable rupture of the gall-bladder, in which, after five weeks, he evacuated over three gallons of bile-stained fluid, yet the patient recovered. Moreover, there is probably a considerable escape of bile into the abdomen in some of the cases of cholecystotomy which recover ; yet it is an accident that should be avoided if possible.

This fear of the escape of bile led me to insert a glass drain in the present case. Part of the tumor was removed by enucleation and part by the cautery; and I feured that either surface or both would allow of the escupe of bile since the sutures did not, of course, accurately approximate the surfaces. The result showed that the precaution was needless, and after forty-eight hours the drain was removed, no bile or bile-stained fluid having been observed.

It being conceded, then, that more or less of the liver could bo removed without sacrificing life, either primarily or by its after consequences, the next point is

(9) T'ine method of removal and especially the means for the prevention of hemorrhage. - In my own case there was absolutely no trouble in this respect. The base of the tumor was severed by repeated small touches of the cautery-point; the large vessels were all seen and ligated before their division by the cautery ; and the small ones either did not bleed or ceased bleeding upon slight touching with the dull red platinum point or after pressure with a sponge dipped in hot water. From the portion that was enucleated by the thumb-nail, absolutely no hæmorrhage other than slight oozing took place, and I would especially commend this procedure. It was simple, easy and rapid. The methods adopted in the other nineteen reported cases have been various; and often, as in the present case, two or more have been combined with great advantage; thus the tumor has been excised; ligated and excised; ligated and canterized; ligated, excised and cauterized; and in three cases was enucleated.

(10) 'Ireatment of the stump. - In nine cases, after completion of the operation by the methods already named, the stump was returned to the abdominal cavity. In three cases the lips of the hepatic wound were first sutured, in one of them (No. 17) with as many as sixteen sutures. Of these nine all but one recovered. In six cases (Nos. $2,5,6,7,13,16$ ) the stump was sutured in the abdominal wound at the close of the operation. In two (Nos. 5, 7) there was a free discharge of bile through the wound. All of these recovered. In four cases (Nos. 12,14, 18, 19) the liver was attached to edges of the abdominal wound before the removal of the tumor. In one case (No. 14) ligation of the pedicle, fixation to the abdominal wall and immediate amputation of the tumor was practised; but in the other three a true extra-peritoneal treatment was carried out. In one case (No. 12) it was done in two stages, that is, primary suture to the abdominal wall and a later amputation. Liicke (No. 18) sutured the pedicle to the abdominal

7 Lanoot, 1891, 1, 1091. wall, surrounded the protruding tumor with iodoform gauze, and tied the pedicle with a rubber-tube, which was gradually tightened. 'Terrillon (No. 19) made an artifcial pedicle $\left(24 \mathrm{~cm} .,\left[9 \frac{1}{4} \mathrm{in} .,\right]\right.$ in circumference) by constricting the attachment by rubber-tubing and sutured it to the abdominal wound, the tumor protruding externally. Under an iodoform dressing this gradually withered, and was removed on the seventh day. All of these four extra-peritoneal cases recovered.

(11) Results. - In one case (No. 12) the result is not known. Of the other nineteen, seventeen recovered, and only two died, one on the day of the operation, presumably from shock, the other on the twelfth day, from sepsis.

\section{(12) Conclusions:}

a. Both experiments on animals and operation on man have shown that tumors of the liver, and even large portions of the liver itself, can be removed without undue disturbance of the function of the liver; the experimental evidence makes it probable that the livertissue may be regenerated and the loss made good.

$b$. That the escape of bile into the peritoneal cavity is not a usual phenomenon after such an operation; that it may generally be prevented either by searing the raw surface of the liver, by ligation, or by securing the stump in the abdominal wound, and that, even if the bile so enters the peritoneal cavity, the result is not necessarily fatal.

c. Hxmorrhage need not be greatly feared. The vessels can often be tied separately or in mass, or cut through by the cautery, or controlled by pressure, or by a combination of these means.

$d$. The resection or amputation is best done by enucleation, by the cautery or by the knife or scissors, preferably perhaps in the order named. In case of a tumor with a very large base of attachment, the operation may be done in two stages, the base being surrounded by an elastic ligature in the interval.

$e$. The mortality thus far has been ouly about ten per cent.

\section{GALL-BLADIER SURGERY.}

(a) Onk Cask of lmpacthe Gate-Stonks ; Perforation ; DRATH WITHOUT OPKIRATION. (b) FOUR FXpIORATURY Ophrations on whe Gali-Blamink. (c) Six Cholheysto'romes fole Gali-Strones.

W MAURICE H. RIOHARBOA, M.D.

MY attention was first called to the importance of gall-stones by a case which occurred in the practice of Dr. S. J. Mixter some ten years ago. He will remember a woman who passed a very large gall-stone, at least an inch and a half in diameter, by rectum. Later this patient died from acute intestinal obstruction caused by the lodgement of another stone so large as to obstruct entirely the lumen of the bowel. This condition must be considered infrequent if not unique : but it shows one of those rarer conditions which may occur after the dislodgement of an impacted stone and its escape into the intestine.

During the Hext six or eight years I saw occasionally cases of biliary colic, soon relieved by the escape of the stone. I have made it an invariable rule to examine the faccal discharges for at least a week after an attack of biliary colic. My method has been to pass the fieces through a fine-meshed sieve, myself. Great care has to be taken in many cases not to crush the soft and recently-formed stone. The importance 
of this procedure, I think, will appear in the cases which I have to report. Had such care been taken early in the history of my operative cases, the diagno. sis would have been very clear indeed. So carelessly have these investigations been made, when they have been made at all, that I have not been willing to eliminate the existence of gall-stones from the fact that none have ever been discovered in the discharge. recall one cuse very distinctly in which there was a clear history of biliary colic, and where at the end of a weck I found a small, bright yellow stone of very recent formation, which without the most careful manipulation would have been crushed in passing the facal discharges through the sieve.

Before reporting this evening those cases of prolonged and unnecessary suffering which have been entirely relieved by operative measures, I wish to report in considerable detail one of those lamentable occurrences which have not been infrequent in the history of medicine, and to avoid which is one of the chief ob. jects of this paper. I refer to the case of a young woman, prominent in society, with a young family and with everything to live for, who died from the perforation of the common duct by an impacted stone, with all the symptoms of a general peritonitis. In this case, as in all other cases to be reported, the matter of diagnosis was of the first importance. It is very necessary for us to differentiate impacted gall-stones from malignant discase. The distinction between certain cases of gall-stone impaction and cancer or tumor pressing upon the duct aud causing jaundice is at times very difficult. Some of the most skilful diagnosticians have erred in this respect. In most of the cases published herewith, some experienced man has been mistaken. In the majority of cases the symptoms are almost entirely subjective. There are no physical signs whatever on which we may depend for diugnosis, beyond jaundice and emaciation. The histories of the cuses should therefore be taken with great care, and much reliance must be placed upon the patient's statements as to the origin, duration, character and direction of the pain. Believing firmly that the diagnosis must depend more upon the history than upon the physical examination, I shall report most of the following cases in some detail as to their subjective symptoms. The statements of the patients which have any bearing upon the diagnosis $I$ have reproduced from my short-hand notes. As will be seen in all of them, whether simple exploratory incision or cholecystotomy for the removal of stones, with one or two exceptions, there have been no local physical signs whatever.

(a) GALL-STONE IMPACTLD IN TIIE COMMON DUCT; PERTORATION; DEATII WITHOUT OPERATION.

Casic I. Mrs. 'T. D. P., aged thirty. First examined December 3, 1888 . Married seven years; three children; two miscarriages; belongs to a family who have all died at about widdle age or young. Father died of consumption; one brother died of appendicitis; a sister died at sixteen of some mesenteric trouble; another of Roman fever in Florence; one sister living and well; one brother living and well; one paternal uncle died of consumption; another lived until he was fifty and died of some brain trouble; grandmother now living.

Mrs. P. has been troubled with epilepsy. Has had post-partum hamorrhage twice. More or less womb difficulty. With the exception of the epilepsy and the uterine trouble has always been well. About seven years ago there was cramp in the stomach and colic, just below the right breast. It was a pretty severe pain; would come on any time - night or duy. No vomiting until recently. In the beginning she took sulphate of zinc to make her vomit. This would re. lieve the attacks. 'There seemed to be no connection between the food and the attacks of pain. Of late years the attacks have been of the same kind and constantly more severe. Between the attacks she would be perfectly well. Had a slight attack in July, and in tho latter part of August another, which has persisted ever since. It was preceded by a miserable feeling. Jaundice has been present all the time since $A$ ugust. Movements of the bowels white, and urine very dark. 'The pain in this attack has been in the pit of the stomach, and it was so severe that she could not bear the bedclothes.

Plysical L'xamination. - A large, strong, healthy looking woman, considerably jaundiced. No evidence of disease in the heart or lungs. Urine dark-colored. Nothing in the abdomen. Liver somewhat enlarged. No distention of the gall-bladder could be made out. There was some tenderness in the region of the gallbladder. Pulse and temperature normal.

'This case was sent to me by Dr. Paddock, of Pittsfield, with diagnosis of gall-stones obstructing the common duct. I concurred in this diagnosis, and on November 14th wrote: "It seems to me that this is a case of gall-stones, which has resulted in obstruction of the common duct. I do not believe that anything can be done to relieve gall-stones except surgically. I should not advise operation in this case unless the symptoms are wore severe than they are at present." December 24, 1888: "I am inclined to look upon the case as one of obstruction to the bile from gall-stones. During her visit here I think she has improved. Dr. - L has seen her with me, and looks upon it as a case of neurasthenia, with gastralgia. As far as I am concerned I do not, and have not seen any indications for surgical interference." Early in March, 1889, Mrs. P. was taken with symptoms of violent peritonitis, and on the 5 th I was sent for to open the abdomen. She died a few moments after my arrival in Pittsfield. At the autopsy, a large stone was found in the common duct. Perforation had taken place and the patient had died of peritonitis.

It is quite evident that this most unfortumate result might have been avoided had we known positively that there was a large stose impacted in the common duct. It was impossible to be sure of this, howover, and it was the opinion of one eminent diagnosticiun that this condition did not exist. The symptoms at my last examination were improving, and it seomed after a deliberation of four weeks and a careful study of the caso best to delay. In the light of the experience which I have acquired since, and from the gratifying results which have followed exploration in these cases, 1 should not now hesitate a moment in advising as strongly as possible the necessity of un exploration. While it is well known that stones, even of large size, make their way safely into the intestine, it is certainly not infrequent that a disuster like this results. In a case with a similar history I should not be willing now to take the responsibility of delay. Persistent localized pain with exacerbations accompanied by jaundice, if due to a stone at all, mean a large one hopelessly impacted, and demand interference. 


\section{(b) EXPLORATORY OPLRATIONS ON THE GALL- BLADDER.}

Casie I. 'Tumor of the gall-bladder, due probably to malignant disease; abdomen opened; gall-bladder emptied; cancer of the head of the pancreas pressing on the common duct; death at the end of ten days; autopsy ; cuncer of the head of the paucreas extending into the liver.

C. C. R., aged thirty-nine. Examined September 7, 1889, with Drs. Carlton and Peirson. 'Two years before, an attack of malarial fever lasting four or five weeks, followed by jaundice. Has had recurrence of the fever and the chills since. Eight weeks after the appearance of the jaundice a large tumor was noticed below the liver. The jaundice disappeared about a year ago, and he was perfectly well during the summer. In the spring of the present year the symptoms reappeared with a great deal of malaise. There was considerable loss of flesh; jaundice was present and persistent. Went to Clifton Springs, and in three weeks was much improved. At the end of that time had a gall-stone, which caused great pain for two hours and a half. The gall-stone passed and he felt better than he had for the previous six or eight months. The jaundice did not disappear, although he bleached out a little. The pain was very sharp when the stone passed. He never had had any such thing before. He looked for it in the first discharge, but did not find it. With the exception of these symptoms his general condition was good. Family history good. Loss of flesh excessive. Under the margin of the ribs on the right side, there was a round, fluctuating cumor extending down into the right iliac fossa. 'Two or three hard nodules could be felt at the upper part of the tumor. Very much juundiced and very much emaciated. The tumor was apparently movable. Pulse good and general condition such as to justify interference. Probable diagnosis: malignant disease obstructing the common duct.

On careful consideration of this case it seemed to we probable that the man's disease was maliguant, although there was a clear history of at least one gallstone attack, and that the distention of the gall-bladder and jaundice were due to an obstruction somewhere in the common duct. Exploratory laparotomy was performed on the 9th of September, 1889. Incision was made over the right linea semilunaris, on the edge of the liver, about three inches in length. The liver was found with several small nodules on the under part of the great lobe. 'The gall-bludder was much distended and reached as fur as the crest of the ileum. 'The gall-bladder was emptied through an aspirating needle and about a quart of fluid as clear as water was withdrawn. The hole made by the trocar was sewed up with fine silk. Exploration of the parts revealed malignant disease in the neighborhood of the common duct and the under surface of the liver, The patient died at the end of about ten days. Post-mortem examination showed that there was cancer of the liver with primary disease of the head of the paucreas.

In this case an operation was performed because I was not perfectly certain of the diagnosis. There was very little difference of opinion among those who saw the case that the cause was probably the pressure of a new growth. I did not feel, however, that it was absolutely certain that the cause could not be removed, and this in my opinion, then as now, justified the op- erative interference. The fatal result was not due to peritonitis or any wound infection. The man died at the end of a fow days, as, in my experience, so many do who are much reduced by long-standing malignant disease.

Case II. S. L., aged fifty-eight, painter, married. Massachusetts General Hospital, July 22, 1890. Thirty-eight years ago had Panama fever - chills and fever. Dyspepsia at times. Eight months ago noticed that he was losing flesh and running down. At times troubled with colicky paius and thatus. No vomiting or pain after food. Since then has been losing flesh and appetite. Has lost forty-five pounds. Six weeks ago noticed lump in right hypochondrium, which patient thinks moves and feels like a bladder. Five weeks ago began to be jaundiced. This has increased, with clay-colored stools and intense itching.

No pain or other subjective symptoms. Examination showed marked general jaundice and emaciation. Skin was dry and harsh and covered with excoriations. The tonguo was dry, with slight brown cont. 'There was a large mass in the epigastrium from enlarged liver, on which a small nodule could be felt. IIe vomited about a piut of brownish, muddy fluid on July 12th. No blood was found in the vomitus by the microscope. Stools were clay-colored. On July $22 \mathrm{~d}$, under ether, a vertical cut was mallo over the region of the gall-bladder. The abdominal wall was very thin and lax. 'The gall-bladder was found non-adherent, dilated. The hand introduced into the cavity of the ubdomen could detect nothing suggesting neoplasm. 'There were no stones either in the grall-bladder or in the ducts. The bladder was aspirated and about a pint and a half of pure bile was withdrawn. The fundus of the gall-bladder was then stitched into the abdoninal wound with interrupted silk sutures. The bladder was opened in situ by a one-inch incision. The mucous neubrane was found thickened and injected. A probe was with difficulty passed into the common duct. The bladder was thoroughly washed out with warm water and a rubber drain left in it. The usual dressing, with swathe, was applied. 'There was a discharge of about one ounce of bile daily into the wound. On the 26 th the bowels moved. Stools still clay-colored. Urine the same us before. $\mathrm{He}$ gradually failed, and died on 31 st of July. The autopsy showed cancer of the head of the pancreas.

In this case, which was referred to me from the medical side as a case of probable gall-stone impaction, a fatal result followed the operation, as in the previous case, where the patient was subjected only to the slight dauger of exploration. The wound healed well, and there was no peritonitis. If his disease had been less advanced, or if he had been brought to his state of weakness by a simple obstructive cholamia, I think he would have recovered. 'The case, though fatal, was not 80 from tho operation.

Case III. Mrs. Robert H., aged forty-one, Lawrence. Seen with Dr. Chamberlain on April 9, 1891. A week or two before, Dr. George M. Garland, of Boston, had made a careful examination and advised an exploratory laparotomy. Had the grip ubout a year before, and has not been well since. Has suffered dreadful pain in the stomach during the past summer (indicating the region of the stomach on the left side.) 'The pain has continued more or less for $a$ year. In the previous July fell on a chair striking the left side. The pain comes on suddenly. She be- 
gan to be jaundiced on October 1st. In the begimning the pain was entirely on the left side, and did not go into the right until two months ago. There has been great loss of flesh, without vomiting. Used to have chills. Vomiting has come on within the last six weeks. No abnormal appearance to the vomitus. Stools claycolored; urine dark. She has complained of pain in the region of the right kidney, and there is great tenderness over the gall-bladder. No elevation of the temperature. On examination there was a tumor found in the region of the gall-bladder which shaded off in different directions. It seemed to me to be the liver. I thought at the same time I could feel one or two small nodules. Diagnosis: probably malignant disease of the liver. I concurred in the opinion of Dr. Garland as to the advisability of an exploratory laparotomy on the chance of finding something that an operation would remove. A longitudinal incision was made in the right linea semilunuris over the gall-bladder. The liver was immediately exposed, and, with the gall-bladder, came into view. 'The gall-bladder was normal, but there were numerous cancerous nodules in the liver. 'The wound was closed with interrupted wire sutures. The whole operation did not take over ten minutes. She made a good recovery, and her death, which took place some months later, was not hastened by the exploration, which satisfied physicians, patient and friends.

Case IV. Mrs. I., aged sixty-two, a patient of Dr. Jackson, of Weston, was seen in consultation with Dr. Cutler, who advised an exploration of the gallbladder. Mrs. L. said that she had had bilious attacks and pain, accompanied by chills, for some time. The pain was very sharp in the right side, running to the back and shoulder: also a burning, deep in the right hypochondriac regiou. No real dyspepsia. There is a burning in the side, and at times she cannot straighten up on this account. No loss of flesh; some loss of strength. A small, smooth mass, the size and shape of a kidney, slightly movable, in the region of the right kilney; an enlarged area of hepatic flutness, and an apparent enlargement in the region of the gall-bladder. 'Temperature persistently above normal daily for the past five months. Never more than $102^{\circ}$; usually from $100^{\circ}$ to $101^{\circ}$. Sleep good ; bowels apt to be constipated. The diagnosis was necessarily obscure, but it seemed wise to us all to make an exploration. On November 17, 1891, I made the usual incision parallel with the ribs on the right side until the gall bladder was reached. 'The parts were much adherent to one another, and the omentum was very firmly fastened to the gall-bladder. There was an adhesion also to the hopatic flexure and the beginning of the transverse colon. These adhesions were very carefully separated from the gall-bladder, and, with the hand introduced into the abdomen, nothing could be felt in the common, hepatic or cystic duct. Nothing abnormal could be detected in the region of the pancreas. The gall-bladder was contracted, and evidently had been the seut of some trouble. 'The whole condition was very similar to that found in the cases of prolonged gall-stone impaction, where the gallbludder has become contracted and its walls thickened. Mrs. L. made a very good recovery indeed from the operation, and at first was relieved of the dragging pain of which she complained before. Later she had a good deal of trouble in one shoulder, which had no connection whatever with the operation. I am informed by Dr. Cutler that of late she is somewhat better than she was before the operation, but, up to quite recently, the attending physician, Dr. Jackson, states there has been no benefit whatever from the exploration.

\section{(c) SIX CHOLECYSTOTOMIES FOR GALI-STONES.}

Case I. Mary W. This was the case which was reported in the Jounnal, Vol. CXX, p. 414. She was referred to the hospital by I)r. 'Titcomb, of Concord. She had a history of pain in the side, associated with a very movable tumor on the right, just below the border of the ribs. The opinion was rather in favor of a movable and malignant kidney, though Dr. Titcomb had sent the case in as one of gall-stones. I found it to be an enlarged and distended gall-bladder, from which I removed six stones of moderate size. One was squeezed from the common duct into the duodenum. 'The sac was partially removed, and the base sewed into the abdominal wound. A fistula remained, which closed in a few weeks, and there has beell no trouble since.

Case II. Mrs. C. K., aged forty-eight, married. Massachusetts General Hospital, September 7, 1890. Has passed the menopause. At times has been subject to attacks of quinsy'. 'Three years ago there were chills and fever. One year ago first noticed pain in the right side, coming on gradually. Afterwards the pain was in the epigastrium, and was not associated with ingestion of food. At the same time juundice appeared. This has continued ever since, although at times less marked than at present. Since then there have been several similar attacks of pain, coming on rather quickly, and disappeuring gradually. The pain is of a cutting, raw variety, beginning always in the right hypochondrium and radiating into the epigastrium. The attacks have always been associated with vomiting. Stools greenish. Nothing has ever been found by physicians in the contents of the stools. Ten days ago there was a very severe attack, requiring morphine. There had been none before for a month. Two days ago there was another severe attack. The itching at times is intense. Duration of attack eight to ten hours. 'There has been average loss of flesh. Fuirly nourished; skin saffron yellow; pulse slow, and at times intermittent. There is a trace of albumen in the urine, with an occasional hya. line cast and renal cell. 'Tenderness at the edge of the liver, which can be felt, smooth and regular. Gall-bladder not made out.

On September $9 \mathrm{th}$, under ether, an incision four inches in length was made in the right linea semilunaris from the level of the margin of the seventh rib. The abdominal wall was thick and vascular. Omentum firmly adherent along the lower margin of the liver. The adhesions were broken up with the finger, and the gall-bladder, which was atrophied and Haccid, exposed. A hard, round mass was felt by the finger in the region of the common duct. The bladder was drawn up and opened. With two fingers of the right hand down deep bolow the common duct and with the index-finger of the left hand in the gall. bladder, a stone could be felt as large as a walnut. After some difficulty it was withdrawn. This stone was in the common duct. Another stone was found in the hepatic duct, and was removed in fragments with long, common, polypus forceps. This stone was followed by a copious tiow of bile, which was kept out 
of the peritoneal cavity as much as possible with sponges and irrigation. The gall-bladder was too much retracted and tied down by adhesions to admit of its being stitched to the abdominal wall. The upper lip of the incision, however, was drawn up to the parietal peritoncum, while the lower was left loose. A glass drainage-tube was placed in the gallbladder, and iodoform gauze packed about it. The abdominal cavity was thoroughly irrigated with warm water aud the wound left partly open. The lower half was bronght together with wire sutures and the upper lualf packed with gauze around the tube. large absorbent dressing was applied with rubber pellicle about the tube, and the whole fastened in place with plaster and flannel swathe. The operation lasted one hour and an eighth. In the evening the dressing was stained with bile, which escaped freely froin the tube on its removal. A siphon was arranged to carry off the bile. Patient put upon liquid diet. Thirtysix ounces of bile were siphoned off in the next twenty-four hours.

The patient went on very well indeed for several weeks. The fistula became well established. Jaundice slowly began to disappear. Gauze was removed from the wound on the 13 th. The wound was clean. On the 19th the faces were slightly stained with bile. On the 25th there was a discharge of very foul pus from the wound. The temperature had been up for some days. 'The pain in the back and right side, which had been constant for several days, gradually disappeared after the discharge of pus. 'Temperature became normal. Siphonage was omitted. Later the tempernture kept rising, and the general condition was worse. There were chilly sensations and fever. The malarial history was thought to account for the chills. On the 29 th an opening was made in the lower part of the wound communicating with a pus cavity which contained about half an ounce of pus. The opening was dilated and the cavity syringed out. Siphonage begun again. On October $2 d$ there was a elight discharge of pus. The amount of bile was reduced to fifteen ounces. There was considerable romiting. 'The temperature at times rose to $104^{\circ}$. She died on the 10th of October.

At the autopsy a gauze sponge was found at the bottom of the pus cavity, from which there had been an intiltration posteriorly, and from which the patient died septic.

In this case, at the time of the operation, it seemed to me that we had a most formidable condition of things. The gall-bladder was badly torn, and it was so contracted that it was out of the question to think of trying to sew it to the abdominal wound. The long obstruction to the flow of bile had dilated the liver-ducts to such $a$ degree that large quantities of bile were stored there, ready to pour out over the wound and into the abdominal cavity the moment the obstruction should be removed. When the stone was removed from the hepatic duct, there was an abundant escape of bile, much of which covered the intestines and escaped into the peritoneal cavity. This formidable omergency could be met only by making anastomosis between the gall-bladder and intestime, or by closing entirely tho bladder by suture, or by doing as 1 did at the time, putting a tube into the hepatic duct and tying the gall-bladder, or its remains, about the glass tubo. In this case, as in severul subseynent ones, this method has proved perfectly satisfactory and successful.
During the operation large quantities of bile es. caped, in spite of all efforts to prevent it, und covered the surrounding parts. The immediate effect of the introduction of the tube with the gauze packing was to shut off the rest of the abdominal cavity. On removal of the gauze, the general cavity of the abdomen was entirely and firmly protected by the recent adhesious.

The method employed at that time to prevent the leaving of sponges in the abdominal cavity was to have a special nurse whose duty it was to count the sponges before aud after the operation, to watch such as were introduced into the abdominal cavity, and to be responsible for them as far as possible by devoting her atten. tion to nothing else. At this operation the nurse counted the sponges very carefully before and twice after the operation, and reported them all present. It seemed to me at the time that these precautions were ample, and as thorough as any taken elsowhere. The lesson which I have learned is to have more than one count made by at least two different persons, both before and after the operation.

Casv III. Harry K., aged twenty-four, detective. Massachusetts General Hospital, October 1, 1891. After leaving the hospital where he was in the spring of 1889 , with siwilar symptoms, which were not treated surgically, he felt perfectly well until September 15 th, when he had a severe attack, which lasted four weeks. Since then he has had six or seven attacks at iutervals of from three to five months. The interval increased and the duration of the attacks diminished until the present one, which has continued since August 2\%, 1891. He has received all kinds of treatment, including massage. Morphia is the only thing that relieves him. Ether makes him crazy. When in pain he does not know what he is doing, though he can tell you afterward. The pain comes on suddenly. It starts in the pit of the stomach and travels through the right hy pochondrium into the back. In some of the attacks be has been juundiced. Bowels wore constipated. 'Ihere was blood in the dejections at times. He has lost considerablo in weight the past two years. He has taken a great deal of morphia (nearly a grain, if not more) a day. When seen in the ward, the patient was very nervous and apparently in some pain. Attacks of pain came on about 3 1. M. This patient was examiued by most of the physicians and surgeons in the hospital. Some advised operation, and others did not think it necessary. 'Ihere was a good deal of doubt expressed as to the presence of auy foreign body in the gall-bladder. Dr. F. C. Shattuck, who turned the case over to me, insisted that a stone was present, which proved to be so. On October 6th an incision six inches in length was made parallel to the ribs and below the edge of the liver. It was carried well into the tlank. 'The abdominal parietes were thick and muscular. 'The haud was introduced into the abdomen, and the gall-bladder found and drawn into view. The parts about tho gallbladder were slightly adherent to it. A small stone could be felt through its parietes. Over the stone the bladder wall was very thin and friable, and had every appearance of being about to be perforated. The bladder was incised, and a small, sharply angular stone removed. 'The wall was too friable to suture to the abdominal wall, and therefore a ligature was passed around the bladder near its base, and tho whole removed. Previously a probe showed that the common 
duct was patent. 'The lower end of the incision was closed with silk and wire. 'The upper end, about the stump of the gall-bladder, was packed with iodoform gauze, which was brought out of the wound. Dry dressing was applied. On the next day the dressing was stained with bile. The stitches were out on the 13th. The patient made a slow but gratifying recovery. He was very nervous, and seemed to suffer much for some weeks. 'The gau\%e was entirely removed on 23d. He was discharged from the hospital in November, and has remained well up to the present time (April 14, 1892).

In this case there was a good deal of difference of opinion, some thinking that there was nothing mechanical to cause the pain, and others being quite confident that a gall-stone was at the bottom of the trouble. The situation and impaction of the sharp stone, with the ulceration and inflammatory condition of the parts, seemed to me quite sufficient evidence that the whole trouble was caused by the calculus. Ilis perfect recovery justifies the diagnosis and the operation. (Patient exhibited.)

Cass IV. George F., aged fifty-eight, gentleman. History of gall-stone extending over eight years, with occasional attacks of jaundice. Great suffering and almost complete disability. Referred to me by I)r. J. P. Oliver. Diagnosis confirmed by Dr. Fitz.

Operation on October 10, 1891, at St. Margaret's, assisted by I)r. Mumford. An incision parallel to the ribs was made just at the outer border of the rectus abdominis. 'Through a small space free from muscular tissue the gall-bladder was exposed by a small incision and the fingers introduced into the abdomen. A row of gall-stones could be felt in the cystic and common ducts. 'The base of the gall-bladder, which was in contact with the anterior abdominal wall, was united to the wound by numerous interrupted silk sutures. On opening the gall-bladder bile immediately escaped, and seven large stones, one after another, were removed from the cystic luct. By means of the polypus forceps the last stone, which projected into the common duct, was removed - the stowe which had caused the jaundice in this case. After the operation a drainage-tube with siphonage was introduced into the gall-bladder. 'The patient made a rapid recovery, but a fistula still persists, and will probably require a secondary operation to close it. In this case, as in the first, the obviously safe method was to sew the bladder to the abdominal wall. There was nothing diflicult about the operation.

CAsE V. Mrs. L. L. W., aged thirty-seven, referred to me by Dr. George $M$. Garland, consulting physician, and Dr. Knight, of Milford, Muss., attending physician, December 15, 1891, entered the Massachusetts General Hospital. Present trouble began with pain in the stomach at the age of seventeen, which lasted about an hour. Had a few similar attacks, and then went two years without pain. From that time to the present there has not been a whole year without pain. First noticed juundice a year ago. It was accompanied by pain and vomiting. No blood; urine dark. 'The pain was sharp and came on suddenly, lasted a few hours, and then went away. Jaundice came on a few days later. Has been jaundiced for the past year. Pain has been growing worse, so that she has been unable to work. Has had three or four attacks since last year. Diagnosis : gall-stones impacted in the common duct.
On December 29, 1891, an incision five inches in length was made, parallel to the ribs, on the right side. The incision was enlarged for the introduction of the hand. 'The gall-bladder was found with some difliculty, on account of the numerous adhesions. It was contracted and could not be brought in contact with the anterior abdominal wall. Stones could be felt in the common and hepatic ducts. An opening was made in the fundus of the bladder, and eight stones were removed from the common and hepatic ducts. One large stone was so firmly impacted in the common duct that it was impossible to stir it before it had been completely broken up by common polypus forceps, which in my opinion, is the best instrument for this purpose. The duodenum presented in the wound throughout the operation, and the manipulations of the stone with the right hand had to be made through the layers of the duodenum. During the manipulations large quantities of bile were discharged over the parts, which were washed off with warm water from time to time. 'The stones which were detached from the common duct would becone lost in the dilated hepatic, and quite prolonged manipulations were necessary to recover them. A glass tube was placed in tho hepatic duct, and iodolorm gauze was placed about the tube down to the base of the gallbladder, which had become much torn by the manipulations. A dry dressing was applied. 'There was considerable flow of bile. The stitches were removed on January 6 th, and the gauze was out at the end of a week. January 9th the tube was out. A gauze drain was left in position. Bile was first noticed in the stools on January 18th. On February 10th the wound was entirely healed. Jaundice had then nearly disappeared and she was feeling as well as ever. She was discharged on the $16 \mathrm{th}$ of January, and has remained perfectly well ever since.

Casi VI. Elbridge B., aged fifty-two, referred to me by Dr. Fessenden, of Salem, and by Dr. C. F. Folsom, consultant, of Boston. Previous health good. Present trouble began with what he thought to be an attack of acute indigestion, after euting chestnuts, about eight years ago. The pain was described as "dreadful distress." A dose of morphine relieved him and he got up the next morning all right, that is, all right as far as the distress was concerued. He was very yellow for some days. 'The next attack was last July. He had jaundice, but no pain, nothing but " a miserable feeling all over." At other times it would bo what he called a "horrible feeling." His weight was reduced from 170 to 125 pounds. The liver could easily be made out, but nothing else could be detected by examination of the abdomen. He was deeply jaundiced.

Operation was performed at St. Margaret's, on Februaly 9, 1892, assisted by Dr. W. A. Brooks. An incision was made on the right side parallel with the margin of the ribs, at the outer border of the rectus abdominis. This brought me down upon a small muscular space at the outer border of the rectus just over the normal position of the gall-bladder. On cutting through this and exploring with the finger, I could feel gall-stones somewhere in the regrion of the common duct. 'The incision was enlarged downwards and outwards, and upwards along the outer border of the rectus, making a semilunar incision with the convexity downwards and to the left. 'The liver was distinctly enlarged and projected about two inches 
below the border of the ribs. It was dark in color and had a congested appearance. In the sulcus where the gall-bladder was situated the omentum was firmly adherent, not only to the sulcus itself and to the under surface of the anterior border of the lobe, but to the fundus of the gall-bladder. There were no other adhesions. The gall-bladder was contracted and its walls were thickened. It was impossible to separate the adhesions of the omentum and the liver without tearing; I therefore clamped them and tied them off. 'I'his brought the fundus of the gall-bladder, from which the adhesions had just been cut, into view. An incision was then made into the fundus large enough to admit the finger. The whole lumen of the gall-bladder was not larger than the index finger. On dilating with the finger at the cystic duct, there was a sudden large flow of bile which pushed before it a large gall-stone three-quarters of an inch in diameter, faceted. 'This was followed in a few moments by another. I then dilated the cystic duct a little further and could feel another gall-stone, which I delivered with the forceps, having first crushed it. No other stones could be detected through the interior of the gall-bladder. I therefore inserted my right hand into the abdomen, and feeling through the stomach and duodenum detected a mass of gall-stones apparently lodged in the common duct. These, without much difficulty, were detached and pressed up into the hepatic duct, into the liver, beyond the opening of tho cystic duct. With a great deal of difficulty I managed to squeeze them out through the cystic duct, and two more were delivered uninjured. The last one I cuught with the common polypus forceps high up in the hepatic duct and removed. The operation, from the time of the ether until the end, occupied forty minutes. 'The wound was occasionally irrigated with warm water during the operation, and the parts were protected from the escape of bile, as well as possible, by packing with sterilized gauze. 'There was considerable hamorrhage from the liver at the point of the separation of adhesions. 'The patient's condition during the operation was excellent. It was impossible oven to approximate the walls of the gallbladder to the abdominal wound. I therefore put a glass drainage-tube through the gall-bladder into the hepatic duct, and packed around carefully with sterilized gauze and applied a rubber tube to the end of the glass tube for siphonage. This gentleman made an uninterrupted and rapid recovery, and was discharged from St. Margaret's, perfectly well, on the 25 th of March. It took about three weeks to remove the gauze, little by little. At the end of that time the passage of bile through the common duct had become fully established. In a short time the abdominal wound was entirely closed by grauulations, and the patient increased very rapidly in flesh and strength. The jaundice hrd almost entirely disappeared at the time of his discharge.

'The most important factor in the diagnosis of gallstones is the history. Physical examination adds very little, if unything, to it. Recurrent attacks of pain with transitory jaundico, persistent discomfort extending over a long period of time, accompanied even with a general cachexia, unless the ansemia is steadily progressive, are the most important diagnostic points in the distinction from cancer. Several patients upon whom I have operated, and others where I am cousidering the question at the present time, de- scribe their discomfort as a "terrible distressed feeling," rather than actual pain. I have been struck by the similarity of the expressions used to give an idea of their sufferings. The presence of a dilated gallbladder does not accompany the one condition any more frequently than the other. Patient examination of the discharges after an attack should be made, and all the faces should be passed through a fine sieve. Even the most experienced diagnosticians, however, may be mistaken. In most of my cases some one eminent medical man has been nistaken. I refer again to this fact to justify the opinion that in all cases where there is any doubt, the patient should be given the benefit of it, and an exploration should be made.

'The prognosis in cases of long-continued impaction is certainly grave. In most of my cases I do not believe that Nature would ever lave effected a cure, or not without great danger of some serious disaster, as in the first case reported. 'The prognosis after operation seems to me very encouraging indeed. With the exception of the second case of cholecystotony, all have recovered, not only from the operation but from the symptoms demanding it. In the second case, I think I can claim recovery from the immediate dangers of the operation, and while the sponge was doubtless the direct cause of death, this accident could hardly have been provided against more carefully than it whs at the time. I think that I can say that fow men at that time took any more effective precautions than to have one experienced nurse whose duty it was to attend to the sponges and nothing else. The lesson I have already emphasized, is to confide that duty to no less than two individuals.

The best cut for operation, the extent of which is uncertain beforehand, is, in my opinion, that which starts a little to the left of tho linea semilunaris, an inch from, and parallel to, the margin of the ribs, and carried across the fibres of the external oblique. At the outer border of the rectus there is a small space quite free from muscular tibre where the fundus of the gall-bladder is generally in contact with the peritoneum. At times the tranversalis fibres intervene. Through this spot the bladder may be explored with one or two fingers. If necessary, the cut may be continued upwards along the outer border of the rectus, and downwards and outwards parallel to the margin of the ribs. In this manner a very satisfactory view of the parts may be obtained.

In most cases of long standing I lave met with adhesions. At times it is very difficult to separate them. If it complicates or delays the operation there is the advantage of being less danger of bile escaping into the abdominal cavity. 'The fourth exploratory operation shows that a part of the discomfort, at least, may have been caused by the loaded colon dragging upoin the gall-bladder.

If the bladder is loose and presenting, it should be sewed to the abdominal wound, once having.completed the exploration of the common duct, and having become satisfied that in order to detach the stone it will not be necessary to have one hand in the abdowinal cavity outside the gall-bladder. The line of suture having been completed the bladder may be opened.

Where the gall-bludder is contracted upon a stone, or is 80 inelastic that it cannot easily be drawn to the abdominal wall, or where it is necessury to open the common, hepatic of cystic duct, I believe there is no 
method so rational or so successful as that employed in four of my cases (Fig. 1). A glass-tube fitted into the open duct and packed about with gauze, with the addition of siphonage, gives a most excellent and satisfactory drainage, with which $I$ have as yet seen no bad results. 'This method may be applied to any condition of obstruction or impaction (Fig. 2).

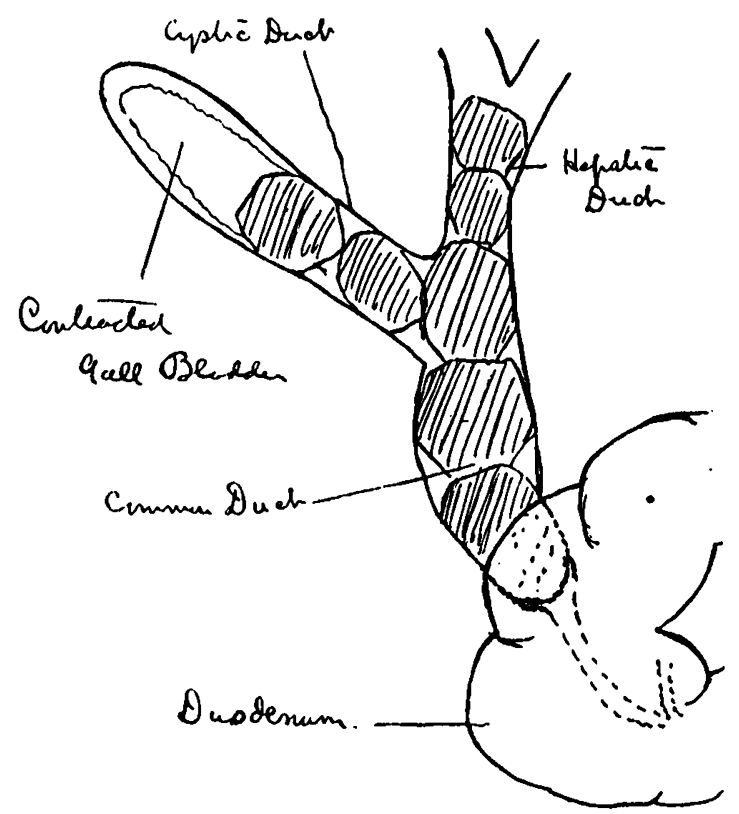

Fio. 1. Diagram showing position of stones in Cases II, V, VI.

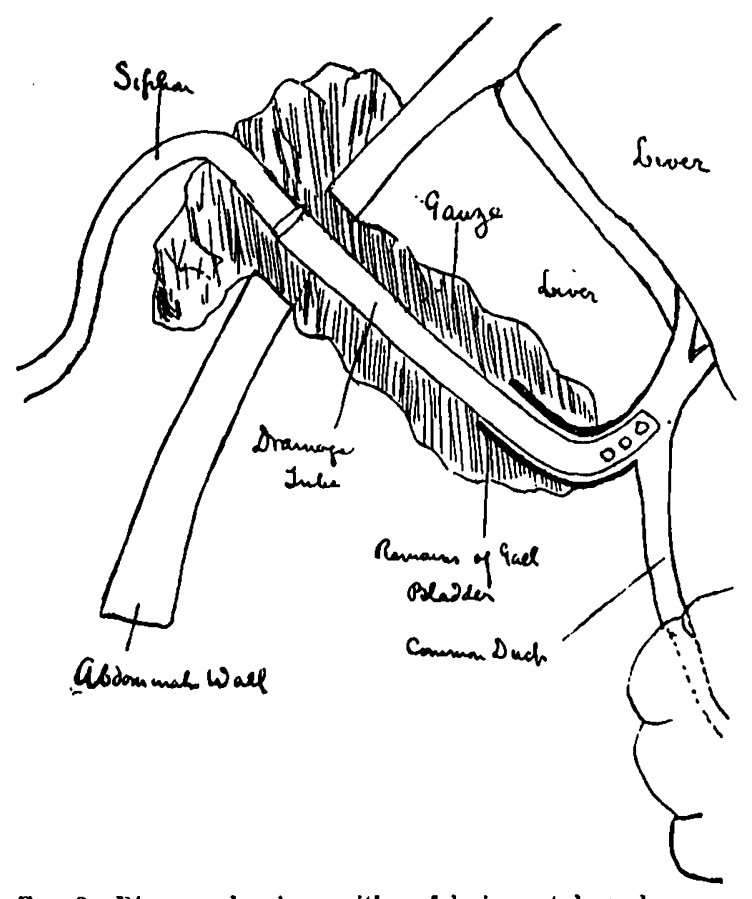

Fug. 2. Diagram showing position of drajnage-tube and gauze.

The gauze should be removed gradually until all is out. I have seen most gratifying results follow this method of shutting off the general cavity of the peritoneum in operations for appendicitis and intestinal resections. The gauze, through its meshes, exercises an irritating effect which causes an almost immediate adhesive peritonitis.

The effect of bile escaping in large quantities into the wound seems to be negative. In no case has there been any ill effect. It must have escaped in considerable amounts into the region of the gall-bladder in most of the operations. The anatomy of the parts, however, would tend to confine the fluid to the immediate vicinity of the foramen of Winslow. The transverse mesocolon and the hepatic flexures of the colon prevent bile escaping except in the right flank. The duodenum, pyloric end of the stomach, and the lesser cavity of the omentum through the foramen of Winslow, would be the only parts immediately invaded, and all these are apt to be shut off by adhesions in long-standing cases.

Patients suffering from symptoms of hepatic colic who have advanced into a profound choliemia do not seem to offer as tavorable proguosis as more recent cases, nor to be so favorable for operative interference. The stone is likely to be larger, and the danger of ulcerative processes greater, and the patient seems to run greater risks from attempts at relief; yet, so far as my observation and experience go, the most advanced cases have done as well as the most favorable ones, and I think the time has come when we should. advise all patients, where a moderately certain diag. nosis has been made, that after waiting a reasonable time for Nature to effect relief, the chances for recovery and usefulness are better when we resort to modern surgical art.

\section{SECONDARY LAPARO'TOMY FOR PISTOL WOUND OF THE LIVER, WI'TH A REPOR'T} OF A CASE. 1

\footnotetext{
BY HoMke GAGK, A.M., M.D.
}

Surgeon to Worcester City Hospital and to Memorial Hospital.

THe natural history of wounds and injuries of the liver, aside from the interest which attaches to the subject of itself, is of interest because it illustrates the extent to which mutilation of the liver is possible without interference with its function, and because it illustrates the natural processes of repair. 1 desire, therefore, to present the following case with a few observations suggested by its occurrence.

On July 5, 1889, Frank M., aged fifteen, discharged a toy pistol, loaded with a blauk metallic cartridge, with the nozzle held firmly against his jacket. It burnt a hole through his clothes and made a wound in the abdominal wall in the right hypochondrium, two iuches from the median line and an inch below the margin of the ribs. 'There was but little hienorrhage from the exterual opening, and but little shock, and the wound, which was supposed to be purely superficial, was cleansed and closed. During the night he had very severe pain, and for ten days was confined to the bed. On getting up, it was found that he could neither stand nor sit upright, on account of pain in the region of the wound, but at no time was he regarded as very sick, and there was said to have been no rise of temperature. Within a few days the pain became more severe and he was obliged to return to bed. Then, for the first time, was noticed a decided fulness on the right side, with increased pain and tenderness, associated with progressive weakness and some rise of temperature.

I saw him first three weeks after the injury. He was decidedly undersized, pale, and much emaciated, 1 Read boforo the Surgioal Soction of tho Sulfolk District Medioal Soolety, March 2, 1892 . 